\title{
ScreenSpot Resource Discovery for Smart Spaces and MobileVue Media Sharing Application
}

\author{
Marko Jurmu \\ MediaTeam Oulu \\ Department of Electrical and \\ Information Engineering \\ Univ. of Oulu, Finland \\ marko.jurmu@ee.oulu.fi
}

\author{
Sebastian Boring \\ Media Informatics Group \\ Department of Computer \\ Science, University of \\ Munich, Germany \\ sebastian.boring@ifi.Imu.de
}

\author{
Jukka Riekki \\ Intelligent Systems Group \\ Department of Electrical and \\ Information Engineering \\ Univ. of Oulu, Finland \\ jukka.riekki@ee.oulu.fi
}

\begin{abstract}
This paper documents the demonstration showcasing the ScreenSpot resource discovery framework and the MobileVue social media sharing application. The key points of the demonstration include: requesting multidimensional resource availability information from a smart space and visualizing this information to the user on a personal device, leasing the selected resource for a distributed application launch and utilizing the leased resource to deploy an application for personal media viewing, manipulating and sharing. This application then allows users a 3D sensorbased interaction between their mobile phone and a large public display.
\end{abstract}

\section{Categories and Subject Descriptors}

C.2.4 [Computer-Communication Networks]: Distributed Systems

I.3.6 [Computer Graphics]: Methodology and Techniques

\section{Keywords}

Ubiquitous computing, resource leasing, mobile phones, 3D sensor input, media sharing.

\section{MOTIVATION \& RELATED WORK}

For several years, digital media succeeds in our everyday life. Through the introduction of smart handheld devices with media capturing capabilities and sufficient storages, people start to have ultra-portable media storages with them. Naturally, as an emergence of this development, the need for media organizing, manipulation and sharing has increased.

The portability of these handhelds highly constraints the

Permission to make digital or hard copies of all or part of this work for personal or classroom use is granted without fee provided that copies are not made or distributed for profit or commercial advantage and that copies bear this notice and the full citation on the first page. To copy otherwise, or republish, to post on servers or to redistribute to lists, requires prior specific permission and/or a fee.

MobiQuitous'08, July 21-25, 2008, Dublin, Ireland.

Copyright () 2008 ICST ISBN 978-963-9799-27-1. user interfaces they can support. In the case of media the screen size is of great importance, but also the keyboard is limited when considering email for example. For this purpose, multiple research efforts have studied the themes of UI migration and multi-modal interaction [1-3].

Several terms have emerged for describing the surroundings that support these interactions, such as smart spaces, instrumented environments or ambient intelligence. Similarly, several different architectures have been designed for the technological support of this extension process. In many cases, the architectures have adopted a service-oriented approach, modeling the extensions through commonly agreed service interfaces and allowing clients to discover and connect to these interfaces.

The actual resource allocations of the services, however, are mostly considered trivial and left for the OS layer. We argue that this should not be the case, especially concerning resources that actively participate in distributed used interfaces. Therefore we promote the middleware support for discovering and reserving these ambient resources.

Regarding the viewing of digital media on large displays, research has been conducted in the past [4]. Mostly, these systems address either single user interfaces [5] or rely on direct touch technologies [6]. As direct touch interfaces are often hard to find in public settings, several projects also deal with remote control of large secondary displays. In this field, most of the observed systems rely on 2D input such as the mobile phone's joystick [7]. According to Ballagas et al. [8] however, 3D input-based interaction with remote displays has not been widely examined in the HCI area.

\section{DEMO DESCRIPTION}

The demonstration is aimed to fully cover an exemplary launch of a distributed application structure in a serviceoriented smart space, where the application deals with personal media management. The advantage of the distribution in this setting is in utilizing a large situated display for facilitated media rendering purposes. 


\subsection{ScreenSpot}

The scenario starts with the mobile user wishing to view and share her pictures. She decides to use the MobileVue application, which requires a situated display. So the first task is to discover any displays from the current smart space, along with their associated availabilities and capabilities. As a result of the discovery, the current status of the discovered displays is shown with an integrated view in order to facilitate the selection process.

When a suitable target display is selected, it is reserved by requesting a context-aware lease to it. The request is checked against the service support and the ACL of the target display, and if successful, the lease is granted for the user. The next phase is for the user to proceed (with some guidance) to the reserved target display and authenticate through suitable local connectivity. This can be either an RFID touch or a Bluetooth connection. After the user is successfully authenticated against the lease stored to the target display, the application session can be launched.

\subsection{MobileVue}

Once the application session has been launched, the mobile phone presents a list for selecting images to be transferred to the public display. After selecting a set of images, MobileVue transfers those onto the public display's viewing canvas and the user is able to start interacting with them.

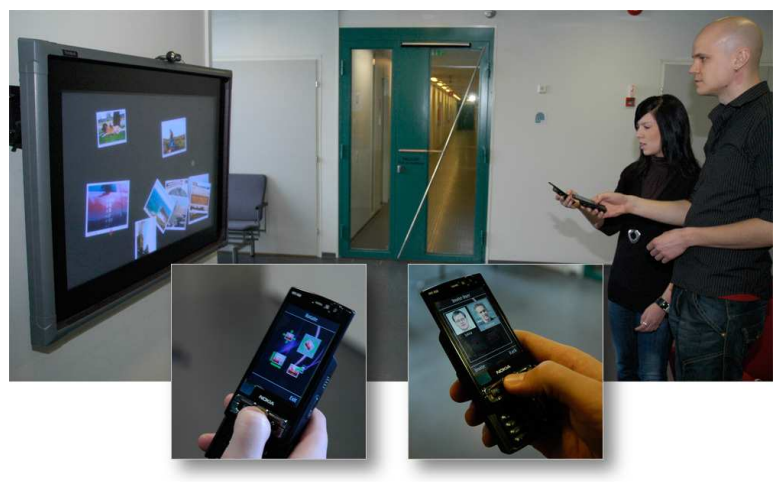

Figure 1. Two persons using the MobileVue application.

The visual feedback is distributed on two displays for each user. While the public display shows the same view for every user, personalized information is shown on the mobile phone's screen. In the case of MobileVue the user interface contains a tool palette for manipulating the images on the screen (see Figure 1).

Using the mobile phone's built-in sensors, users are then able to apply the selected tool shown in their personal tool palette to the image that is beneath the user's cursor on the public screen. Hence, the phone emulates a 3D mouse where the joystick's "select" button acts as the mouse button. Velocity of the cursor is determined by the tilting angle of the phone.

\section{FUTURE WORK}

This research entails multiple future directions. These can be divided between those aimed for the technical support for the resource leasing, and to those concerning the multidisplay interaction and 3D input.

In the resource leasing, challenges are in semantic representations of services, in the injection and extraction of service state information and in the seamless co-operation between the different user groups of the ambient resources.

Regarding the interaction, the separation of UIs (public vs. personal screens) can be used in a variety of applications. In addition, the 3D input seems to be a good technique and should be formally evaluated against standard key-based input. MobileVue encompasses only basic image manipulation techniques, but will be extended towards more interaction possibilities in the near future.

\section{ACKNOWLEDGMENTS}

This work has been financially supported by DFG, GETA graduate school, TEKES and the UbiLife project with its associated company consortium. First author would also like to thank TES Finland for financial support.

\section{REFERENCES}

[1] Pering T., Ballagas R. \& Want R. (2005) Spontaneous marriages of mobile devices and interactive spaces. Communications of the ACM 48 (9): 53 - 59.

[2] Sousa J.P., Poladian V., Garlan D., Schmerl B. \& Shaw M. (2006) Task-based adaptation for ubiquitous computing. IEEE Transactions on Systems, Man and Cybernetics, Part C: Applications and Reviews 36 (3): $328-340$.

[3] Riekki J., Salminen T. \& Alakärppä I. (2006) Requesting pervasive services by touching RFID tags. IEEE Pervasive Computing 5 (1): 40 - 46.

[4] Robertson G., Czerwinski M., Baudisch P., Meyers B., Robbins D., Smith G. \& Tan D. (2005) Large display user experience. IEEE Computer Graphics and Applications 25 (4): 44 - 51.

[5] Frohlich D., Kuchinsky A., Pering C., Don A. \& Ariss S. (2002) Requirements for photoware. CSCW 2002, $168-175$.

[6] Kirk D., Sellen A., Rother C. \& Wood K. (2006) Understanding photowork. CHI 2006, $761-770$.

[7] Silfverberg M., MacKenzie S. \& Kauppinen T. (2001) An isometric joystick as a pointing device for handheld information terminals. GI 2002, $119-126$.

[8] Ballagas R., Rohs M., Sheridan J.G. \& Borchers J. (2006) The smart phone: A ubiquitous input device. IEEE Pervasive Computing 5 (1): 70-77. 